\title{
Assessment of Antenatal Care (ANC) and Demography Parameters on Pregnant Women in Bangladesh
}

\author{
Abu Zafar Al Mansur ${ }^{1}$, Aysha Akter ${ }^{1}$, Towhidul Hasan Mazumdar ${ }^{1}$, Rumana \\ Rashid $^{1}$, Mohammad Asaduzzaman ${ }^{2}$, Babry Fatema ${ }^{2}$, Farha Matin Juliana ${ }^{3}$, \\ Abdul Mannan ${ }^{1}$ Mohammad Sayful Islam ${ }^{4}$ and Mohammod Johirul Islam ${ }^{5 *}$ \\ ${ }^{I}$ Department of Public Health and Nutrition, Primeasia University, Banani, Dhaka, Bangladesh \\ ${ }^{2}$ Department of Biochemistry, Primeasia University, Banani, Dhaka, Bangladesh \\ ${ }^{3}$ Department of Biochemistry and Molecular Biology, Jahangirnagar University, Dhaka, Bangladesh \\ ${ }^{4}$ Department of Pharmacy, Mawlana Bhashani Science and Technology University, Tangail, Bangladesh \\ ${ }^{5}$ Department of Biochemistry and Molecular Biology, Mawlana Bhashani Science and Technology University, \\ Tangail, Bangladesh
}

\begin{abstract}
In recent decades, the improvement of public health area is greatly excelled, but still the mortality rate of infant and child remains unacceptably high. In developing countries like Bangladesh, primary healthcare services including antenatal care (ANC) services are not universally available. In Bangladesh, it is very important to survey the different parameters of ANC that the pregnant women are taking from various maternity clinics and it is also important to know the demographic parameters of these pregnant women for healthy delivery. In this study, ANC and demographic scenario was surveyed on pregnant mothers by including the parameters of ANC such as medication, vaccination, growth monitoring information, resting time at day time, complications/physical problems, change of food intake, net weight gain; and demographic parameters such as religion, educational qualification, family members, marital age, monthly food expenditure. Among 147 studied respondent pregnant mothers, $92.5 \%$ were Muslims and $7.5 \%$ were Hindus; $52.4 \%$ had a family size of $1-3$ members and only $6.8 \%$ had more than or equal to 7 members. $95.9 \%$ of respondents had formal education. It was also found that $81.6 \%$ of pregnant women did not take any medication during their gestational period, 97.3\% had gone through vaccination program, 83\% took 2 hours standard day time rest, $91.8 \%$ gained standard $11.0 \mathrm{~kg}$ weight, $75.5 \%$ were not concern about the nutritional care and the change of food intake during pregnancy. The ANC improved the maternal health and reduced the delivery related complications among the participating pregnant women. We hope this study will make the women much more aware for taking the antenatal care services for their healthy delivery.

Key words: Antenatal Care, Demography, Pregnant Woman
\end{abstract}

\section{Introduction}

The antenatal care (ANC) services that a mother receives during her pregnancy period help to detect and treat complications during pregnancy. It also provides an important opportunity to the well being of the mother and her child. A well-structured and affordable national ANC disseminate health messages to pregnant women and other family members. This maternal health service could improve the timely and appropriate decision for delivery care services.

There is now broad agreement that antenatal care can improve maternal health, which is also an important determinant of infant survival. A study in Bangladesh shows that the women who take ANC services have progressively higher infant survival rates compared to women who did not take ANC (Rathavuth et al., 2007). In developing countries, most maternal deaths occur due to some preventable causes during delivery, which is easily avoidable by choosing the right health facilities for delivery. ANC helps to inform this decision in choosing the right place of safe delivery (WHO, 2001). ANC also helps to disseminate information about the importance of family planning. If mothers have fewer children, then they may have more time to care of their children, which is very important for child survival and growth. ANC ensures tetanus immunization during pregnancies, which helps to prevent infection of the mother as well as her baby.

Maternal nutritional status is considered to be an important factor that affects the successful completion of pregnancy (Abram et al., 1995). The maternal health situation in Bangladesh appears to be poor. Bangladesh is one of the vulnerable countries in the world and the most vulnerable country in South Asian region regarding early motherhood risk (Save the Children, 2004). Growth monitoring during pregnancy is respectively help to control or reduce maternal and infant mortality rate. The maternal mortality ratio was decreased from 228 per 100,000 live births in 2011 to 176 per 100,000 live births in 2015 and the infant mortality ratio was reduced from 37 per 1000 live births to 31 per 1000 live births in Bangladesh (WHO, 2015) ' In extreme cases of chronic 
under nutrition, low energy intake during pregnancy was associated with low birth-weight (LBW) (Eastman et al., 1966). The age of marriage is the most important issues that related to get a healthy pregnancy outcome. The legal age of marriage for women in Bangladesh is 18 years, but a large proportion of marriages still take place before the women reach their legal ages.

Pregnancy within 19 years of age is a public health concern both in developed and developing countries (Chedraui et al., 2004). Around the world, fifteen million women less than 20 years of age bear child which is one-fifth of all births (World Health Organization, 2005). Evidence in developing world indicates that one-third to one-half of women become mothers within 19 years of age, making pregnancy related causes as leading causes of death (Viegas et al., 1992). Relatively, the situation in South Asian countries is severe as there are higher proportions of teenage pregnancies in this region due to common practice of early marriage and social expectation to have a child soon after marriage (Stone et al., 2003).

Evidence further indicates that nearly $60 \%$ of all girls are married by the age of 18 years and one fourth is married by the age of 15 years in South Asia (Mehra et al., 2004), whereas within South Asia, the recorded teenage pregnancy rate is highest in Bangladesh (35\%) followed by Nepal (21\%) and India (21\%) (Acharya et al., 2010).

Steady weight gain during pregnancy is normal and important for the health of the mother and baby. However, it is also important not to gain too much weight. The women who are pregnant, a good approach is to eat to satisfied appetite and continue to monitor weight. For pregnant women, it is recommended that weight gain should be around $11 \mathrm{~kg}$ (24 pounds) during pregnancy (Dutta, 2008). To maintain appropriate weight gain during pregnancy, it is important to choose healthy foods from the five food groups, and limit discretionary foods and drinks high in saturated fat, added sugars and added salt, such as cakes, biscuits and sugary drinks.

The aim of this study was to assess ANC and demographic scenario of pregnant women for safe delivery. In our study, we monitored what percentage of respondent pregnant women took the ANC during their pregnancy period and we surveyed the parameters of ANC such as medication, vaccination, growth monitoring information, resting time at day time, complications/physical problems, change of food intake, net weight gain during gestational period. In the current study, we also observed the demographic parameters such as religion, educational qualification, family members, marital age, and monthly food expenditure of pregnant women. We hope this study will make the women more conscious about taking the antenatal care services during pregnancy for healthy delivery.

\section{Materials and Methods}

Study design: The study was descriptive and used qualitative techniques to monitor the growth of pregnant women attending for ANC at the Azimpur Maternal and Child Health Training Institute, Dhaka.

Study Location: The study was conducted among the pregnant women at Azimpur Maternal And Child Health Training Institute (established in 1953) during February 2016 to January 2017. It is located at Azimpur, Dhaka, Bangladesh. Azimpur Maternal And Child Health Training Institute was chosen for this study because the Lady Health Visitors (LHV) of this institute is engaged in MCH/FP activities and certified as a 'Baby Friendly Hospital' by WHO and UNICEF in 1997.

Study Sample: The study involved pregnant women attending antenatal clinic and had been visiting for the ANC from the first trimester of pregnancy and had weight recorded. However, only those excluded who were not willing to be interviewed or absent from the Maternity Hospital on the date of interview. Initially our target sample was 150 pregnant women. But during data collection due to some missing or abnormal data, we have rejected 3 samples and chosen 147 pregnant women for this study. Finally, a total of 147 pregnant women were selected from the Azimpur Maternal And Child Health Training Institute as study samples.

Sampling technique: Simple random sampling was used to select 147 pregnant women attending at the Azimpur Maternal And Child Health Training Institute to determine the variables of ANC and Demographic characteristics of the pregnant women.

Data collection tool: All relevant previous records of the weight of pregnant women were collected from the maternal health record books. The data collection tool was mainly structured questionnaire for interview. The detail questionnaire was both open and close ended including socio-demographic and economic characteristics.

Pre-testing of data collection questionnaire: The questionnaire was drafted, pre-tested in a similar socioeconomic area and finalized the questionnaire by inclusion of field experiences and suggestions from the field. This was done to ensure the validity and reliability of the instruments.

Data collection techniques: A detail questionnaire was used to collect the information on demographic and socio-economic characteristics, growth monitoring information and food intake information etc. The adult weighing scale (seca M215, Fitness Monitors, UK) was used to determine the maternal weight at certain points during the study period. During weight measurement, each pregnant woman was asked to be barefooted and to remove heavy cloths. 
Study variables: The dependent variable was growth monitoring of pregnant women. The independent variables were: demographic characteristics of the pregnant women, stages of antenatal care attendance, vaccine and medication information during pregnancy, gestational complications, follow up of body weight of pregnant women, pattern of food intake.

Statistical data analysis: All statistical analysis and other data processing were done by using IBM SPSS statistics 22. Data were analyzed in terms of frequency distribution, percentages, mean and correlation was used to find out the association between selected variables. Frequencies, percentages, means, standard deviations and ranges were used to describe the sample. A p value of $<0.05$ statistical significance was used. In order to test for the significance, a one way ANOVA statistic was used.

\section{Results and Discussion}

In the Table 1, the findings of four different parameters (age, religion, educational qualification, family members) were shown. Out of one hundred and forty seven (147) pregnant women involved in the survey, 38 (25.9\%) of them were teenaged (15-20 years) pregnant, 89 were aged between 21-30 years, at the same time 20 respondents were above 30 years old. The mean age of the samples was 24.0 years, with a minimum and a maximum age of 15 years and 39 years respectively. Whilst most of the respondents (92.5\%) were Muslims compared to only $7.5 \%$ Hindus. Also, $52.4 \%$ of pregnant women had a family size of $1-3$ members and only $6.8 \%$ households had $\geq 7$ members. In terms of educational qualification, only $4.1 \%$ of the women had no formal education, $42.2 \%$ had primary education and $16.3 \%$ had Graduate degree.

Table 1: Socio-demographic characteristics (Respondent pregnant mothers, $N=147$ )

\begin{tabular}{|l|l|l|l|}
\hline Parameter & $\mathbf{N}=\mathbf{1 4 7}$ & Percentage (\%) \\
\hline \multirow{4}{*}{ Age (years) } & $15-20$ & 38 & 25.9 \\
\cline { 2 - 4 } & $21-25$ & 43 & 29.3 \\
\cline { 2 - 4 } & $26-30$ & 46 & 31.2 \\
\cline { 2 - 4 } & $31-35$ & 18 & 12.2 \\
\cline { 2 - 4 } & $\geq 36$ & 2 & 1.4 \\
\cline { 2 - 4 } & Total & 147 & 100 \\
\hline Religions & Muslim & 136 & 92.5 \\
\cline { 2 - 4 } & Hindu & 11 & 7.5 \\
\cline { 2 - 4 } & Total & 147 & 100 \\
\hline \multirow{5}{*}{ Educational Qualification } & No formal education & 6 & 4.1 \\
\cline { 2 - 4 } & Primary & 62 & 42.2 \\
\cline { 2 - 4 } & Secondary & 55 & 37.4 \\
\cline { 2 - 4 } & Graduate & 24 & 16.3 \\
\cline { 2 - 4 } & Total & 147 & 100 \\
\hline Family Members (numbers) & $1-3$ & 77 & 52.4 \\
\cline { 2 - 4 } & $4-6$ & 60 & 40.8 \\
\cline { 2 - 4 } & $\geq 7$ & 10 & 6.8 \\
\cline { 2 - 4 } & Total & 147 & 100.0 \\
\hline
\end{tabular}

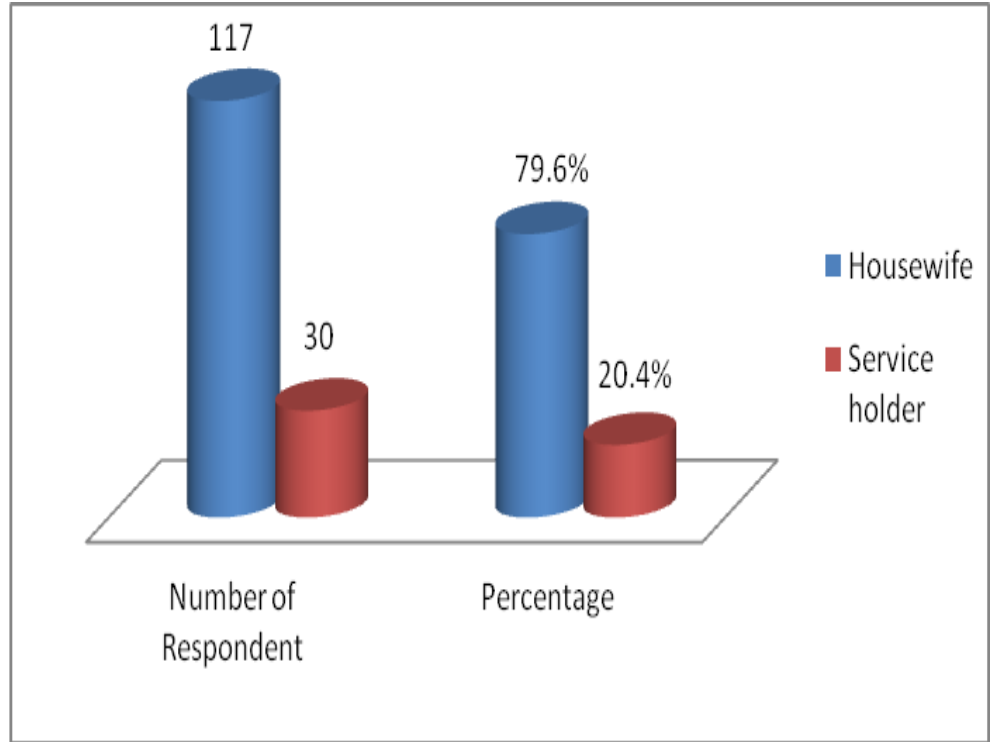

Figure 1: Occupation of the pregnant women 
From figure 1, it was revealed that among 147 pregnant women, 117 were found doing household activities whereas 30 were involved in jobs. This data showed that among the participating pregnant mothers, $79.6 \%$ are housewives and $20.4 \%$ are service holders. This also indicated that one-fifth of the pregnant respondents were involved in service.

Table 2: Monthly income and corresponding monthly family food expenditure of the respondents $(\mathrm{N}=147)$

\begin{tabular}{|l|l|l|l|l|l|}
\hline $\begin{array}{l}\text { Category of } \\
\text { respondents } \\
\mathbf{( N = 1 4 7 ) *}\end{array}$ & $\begin{array}{l}\text { Average } \\
\text { monthly } \\
\text { family income } \\
\text { (Tk) }\end{array}$ & Range (Tk) & $\begin{array}{l}\text { Average family } \\
\text { monthly food } \\
\text { expenditure (Tk) }\end{array}$ & Range (Tk) & $\begin{array}{l}\text { Percentage (\%) of food } \\
\text { expenditure on monthly } \\
\text { income }\end{array}$ \\
\hline LIG (29) & 14,800 & $9,001-20,000$ & 5,000 & $3000-6000$ & 34 \\
\hline MIG (89) & 29,280 & $20,001-45,000$ & 9,985 & $6001-15,000$ & 34 \\
\hline HIG (29) & 60,517 & $45,001-100,000$ & 19,069 & $15,001-40,000$ & 32 \\
\hline
\end{tabular}

The total household monthly food expenditure is a good indicator of the household income and purchasing power. The food expenditure of HIG (high income group) is less compared to MIG (middle income group) and LIG (low income group). This indicates that the rich people don't spend more for buying their food. The income level, as determined by the subject's immediate family's annual income, was shown in Table 2. This table indicated that among the respondents, $89(60.5 \%)$ were belongs to middle income group (MIG). On the other, 29 (19.8\%) were belong to both low income group (LIG) and high income group (HIG). Eventually, compared to the monthly income, the percentage of food expenditure was $34 \%$ both for low income group and middle income group and remaining $32 \%$ for high income group.

Table 3: Age during marriage of pregnant women

\begin{tabular}{|l|l|l|}
\hline Age(years) & No. of Respondents & Percentage (\%) \\
\hline $14-<18$ & 42 & 32 \\
\hline $18->25$ & 76 & 51.7 \\
\hline$\geq 25$ (above) & 76 & 16.3 \\
\hline Total & 147 & 100 \\
\hline
\end{tabular}

The age of marriage is especially important for healthy pregnancy. In Bangladesh, the required ages of marriage for women are 18 years. Because of women aged 15-29 years, they are the most fertility contributing women in Bangladesh, whereas women aged $>29$ years have comparatively lower fertility rates. We have investigated the age of the respondents during their marriage. The table 3 showed that $32 \%$ of respondents got married at the age range of $14-<18$ years. On the other hand, $51.7 \%$ got married $18-<25$ years and also $16.3 \%$ were married at the age of 25 years and above.

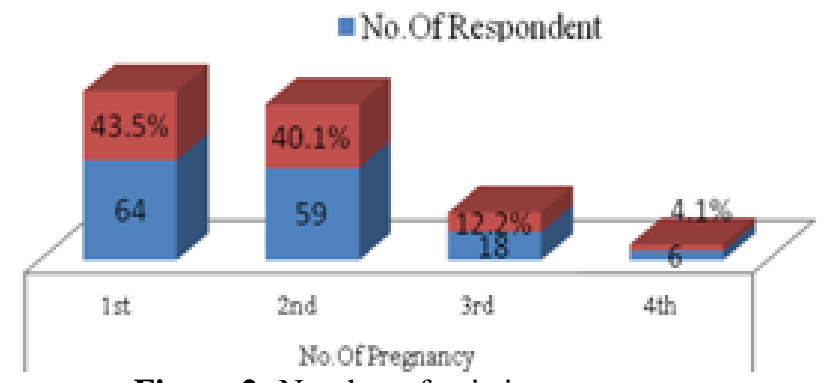

Figure 2: Number of existing pregnancy

According to figure 2, among the total respondents, $43.5 \%$ women were pregnant for the first time and $40.1 \%$ women were pregnant for the second time, $12.2 \%$ and $4.1 \%$ women were pregnant for the third and fourth time respectively.

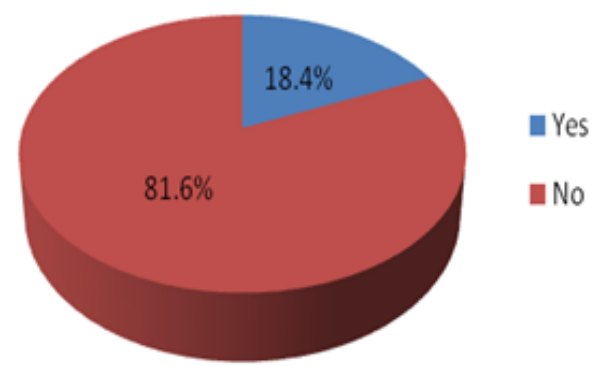

Figure 3: Medication history during pregnancy 
Maternal health problem is the great issue all over the world, especially in developing countries. During this time, every pregnant woman should take monthly checkups from nearest hospital for recovery their physical problems/complications and for getting healthy pregnancy or child birth. The figure 3 shows that the medication history during pregnancy of pregnant women among the respondents. From this figure, we have seen that the significant number $(81.6 \%)$ of pregnant women did not take any medication (even not to take multivitamins or iron tablet) during their gestation period whereas only $18.4 \%$ of pregnant women took medication during the gestation period.

Table 4: Number of ANC visits

\begin{tabular}{|l|l|l|}
\hline No. of ANC visits & No. of Respondents & Percentage (\%) \\
\hline$<4$ & 9 & 6.0 \\
\hline 4 & 129 & 87.8 \\
\hline$>4$ & 9 & 6.2 \\
\hline Total & 147 & 100 \\
\hline
\end{tabular}

Having regular antenatal check-up is an important part of staying healthy and making sure the baby is healthy. Regular checks during pregnancy can assist in identifying and reducing risks both to mother and baby. The World Health Organization recommends at least four antenatal visits during pregnancy. The finding (Table 4) showed that $87.8 \%$ of respondents made it possible to 4 times visit for ANC, which is recommended. Among the remaining respondents, only $6.2 \%$ of respondents made $>4$ times visit and other $6.0 \%$ of respondents made $<4$ times ANC visit.

Table 5: Resting time at day time of the pregnant women $(\mathrm{N}=147)$

\begin{tabular}{|c|c|c|}
\hline Resting time (hour at day time) & No. of Respondents (N) & Percentage (\%) \\
\hline$<2 \mathrm{hr}$ & 25 & $17.0 \%$ \\
\hline $2 \mathrm{hrs}$ & 30 & $20.4 \%$ \\
\hline$>2 \mathrm{hrs}$ & 92 & $62.6 \%$ \\
\hline Total & $\mathbf{1 4 7}$ & $\mathbf{1 0 0 \%}$ \\
\hline
\end{tabular}

Rest during pregnancy simply means decreasing activity level for a period of time. Bed rest during pregnancy increases blood flow to the placenta and can slightly increase a baby's birth weight. Health care provider might recommend a period of bed rest at any point during pregnancy. The table 5 indicates that majority of the respondents took rest during pregnancy. Among the selected samples, the highest number was 92 $(62.2 \%)$ and their resting period was more than 2 hours (recommended is 2 hours) whereas the resting period of $25(17.0 \%)$ of the respondents was less than recommended resting time by ANC.

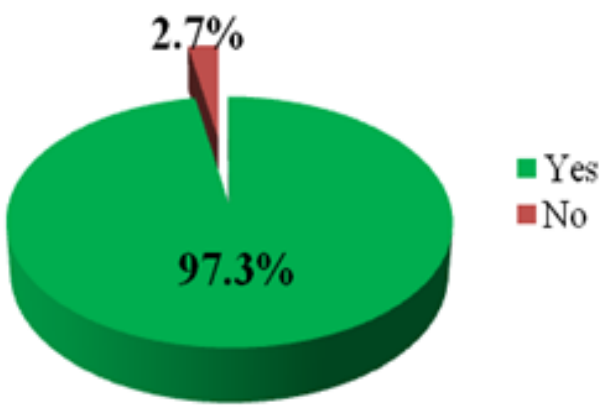

Figure 4: Vaccination records of pregnant women $(\mathrm{N}=147)$

Immunization can protect a pregnant woman and her unborn baby from infectious diseases. Some infectious diseases can cause serious harm to pregnant women or their unborn babies. So, all women should receive vaccines against influenza, whooping cough, rubella (German measles), tetanus and hepatitis B virus during pregnancy. Serious side effects or allergic reactions to vaccines are rare. The figure 4 showed that most of the pregnant women $(97.3 \%$ ) had taken the mentioned vaccines during their gestation period, while only $2.7 \%$ respondents did not take any vaccines during pregnancy. Complications of pregnancy are health problems that occur during pregnancy. They can involve the mother's health, the baby's health, or both. Some women have health problems before they become pregnant that could lead to complications, such as asthma, depression, diabetes, eating disorder etc. Other problems arise during the pregnancy, such as anemia, high blood pressure, fetal problem, miscarriage, pre-eclampsia etc. 


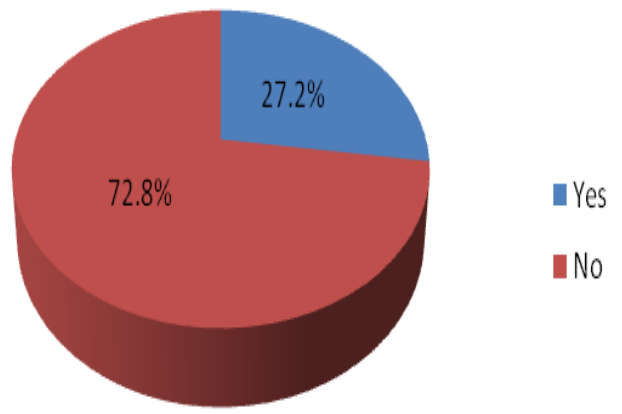

Figure 5: Complications/ Physical problems of pregnant women, (N=147)

The figure 5 showed that higher percentage (72.8\%) of pregnant women did not suffer from any above mentioned complications during their gestational period. However, $27.2 \%$ of pregnant women had some complications like anemia, over weight and obesity. During pregnancy, a pregnant woman needs to eat a total of 2,500 to 2,700 calories per day. These calories should come from a variety of healthy foods. World Health Organization recommended that a pregnant woman should take changed meal through their regular diet during their pregnancy period.

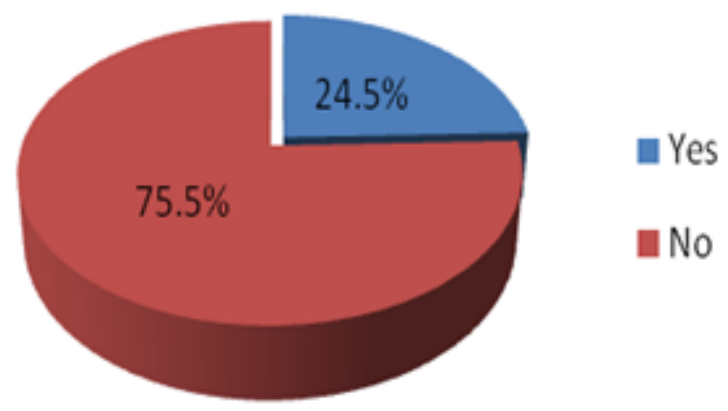

Figure 6: Change of food intake during pregnancy

The figure 6 showed that three-fourth (75.5\%) of the pregnant women did not make any changes in their regular food intake during pregnancy, whereas only $24.5 \%$ of pregnant women have changed their diet during pregnancy.

Healthy weight gain during pregnancy is normal and important for the health of the mother and baby. However, it is also important not to gain too much weight. According to the recommendation of WHO, weight gain upto $11 \mathrm{~kg}$ is normal during pregnancy. Table 6 revealed that $58.5 \%$ respondents gained $11 \mathrm{~kg}$ of weight and $33.3 \%$ of pregnant women gained their weight above $11 \mathrm{~kg}$ compared to recommended values.

Table 6: Net weight gain during pregnancy $(\mathrm{N}=147)$

\begin{tabular}{|c|c|c|}
\hline Weight (kg) gain & No. of respondents & Percentage (\%) \\
\hline$<11$ & 12 & 8.2 \\
\hline 11 & 86 & 58.5 \\
\hline$>11$ (Above) & 49 & 33.3 \\
\hline Total & 147 & 100.0 \\
\hline
\end{tabular}

From the Table 7, it was shown that 41 respondents had taken rest daily more than 2 hours and they gained weight $11 \mathrm{~kg}$ as the recommendation but the effect of resting time on weight was not statistically significant.

Table 7: Effect of resting time at day time on gradual weight gain of pregnant women $(\mathrm{N}=147)$

\begin{tabular}{|c|c|c|c|c|c|}
\hline \multirow{2}{*}{$\begin{array}{c}\text { Resting time at day } \\
\text { (Hours) }\end{array}$} & \multicolumn{3}{|c|}{ Weight gain (In kg) } & \multirow{2}{*}{ Total } & \multirow{2}{*}{ P Value } \\
\cline { 2 - 5 } & $<\mathbf{1 1}$ & $\mathbf{1 1}$ & $\mathbf{1 1}$ & \multirow{2}{*}{0.752} \\
\hline$>2$ & 3 & 18 & 19 & 40 & 44 \\
\hline 2 & 6 & 27 & 11 & 63 \\
\cline { 1 - 4 } & 3 & 41 & 19 & 147 \\
\end{tabular}


The table 8 indicated that most of the respondents (129) went for 4 times ANC visit and among them, 73 women gained weight about $11 \mathrm{~kg}$. On the other hand, only 9 pregnant women went for more than 4 times of ANC visit and among them, 6 pregnant women gained weight about $11 \mathrm{~kg}$ during their gestation period. But the findings were not statistically significant.

Table 8: Effect of ANC visit on net weight gain during the gestational period $(\mathrm{N}=147)$

\begin{tabular}{|c|c|c|c|c|c|}
\hline \multirow{2}{*}{$\begin{array}{l}\text { ANC Visit } \\
\text { category }\end{array}$} & \multicolumn{3}{|c|}{ Net weight gain (In kg ) } & \multirow[t]{2}{*}{ Total } & \multirow[t]{2}{*}{$P$ value } \\
\hline & $<11$ & 11 & $>11$ & & \\
\hline$<4$ times & 0 & 7 & 2 & 9 & \multirow{4}{*}{0.088} \\
\hline 4 times & 11 & 73 & 45 & 129 & \\
\hline More than 4 times & 1 & 6 & 2 & 9 & \\
\hline Total & 12 & 86 & 49 & 147 & \\
\hline
\end{tabular}

Table 9 indicated the effect of educational qualification on weight gain during gestation period. Results indicated that the most weight gain was observed for women with primary educational background.

Table 9: Effect of educational qualification on net weight gain during the gestation period $(\mathrm{N}=147)$

\begin{tabular}{|l|l|l|l|l|l|}
\hline \multirow{2}{*}{$\begin{array}{l}\text { Educational } \\
\text { Qualification }\end{array}$} & \multicolumn{2}{|l|}{ weight gain (In kg ) Total } & \multirow{2}{*}{ P value } \\
\cline { 2 - 5 } & $<11$ & 11 & $>11$ & & \\
\hline no formal education & 0 & 3 & 3 & 6 & \\
\hline Primary & 6 & 48 & 8 & 62 & \\
\hline Secondary & 5 & 30 & 20 & 55 & \\
\hline Graduate & 1 & 5 & 18 & 24 & \\
\hline Total & 12 & 86 & 49 & 147 & \\
\hline
\end{tabular}

Table 10 indicated the effect of age on net weight gain during the gestation period. From this table, we have found that the weight gain of the age limit 21-25 was similar to the recommended value $(11 \mathrm{~kg})$ whereas higher than recommended value $(11 \mathrm{~kg})$ was observed in the age limit of 26-30.

Table 10: Association of age on net weight gain during the gestational period $(\mathrm{N}=147)$

\begin{tabular}{|c|c|c|c|c|c|}
\hline \multirow[t]{2}{*}{ Age Category } & \multicolumn{3}{|c|}{ weight gain (In kg ) } & \multirow[t]{2}{*}{ Total } & \multirow{2}{*}{$\begin{array}{c}\text { Significance } \\
\text { Level }\end{array}$} \\
\hline & $<11$ & 11 & $>11$ & & \\
\hline $15-20$ & 2 & 25 & 11 & 38 & \multirow[t]{6}{*}{0.331} \\
\hline $21-25$ & 4 & 30 & 9 & 43 & \\
\hline $26-30$ & 5 & 19 & 22 & 46 & \\
\hline $31-35$ & 1 & 10 & 7 & 18 & \\
\hline$>36$ & 0 & 2 & 0 & 2 & \\
\hline Total & 12 & 86 & 49 & 147 & \\
\hline
\end{tabular}

\section{Conclusion}

Our study showed that pregnant women who had a positive attitude towards antenatal care (ANC) had a higher proportion of ANC visits than those with a negative attitude. In our study, a significant percentage of pregnant mothers made a recommended number of ANC visits and became benefited regarding maternal health and healthy delivery. It was found that antenatal care helped to improve nutritional nursing and change of food intake, vaccination, weight gain and day time rest during gestational period among educated and non-educated pregnant mothers. From this study, we have also seen that even though a significant number of pregnant mothers were reluctant on their medicational care, but the ANC visits helped them in many ways for their healthy delivery. We hope this type of study will increase the awareness among the women for taking the antenatal care services during pregnancy for healthy delivery.

\section{References}

[1]. Abram, S. B. and Selvin, S. 1995. Maternal weight gain pattern and birth weight. Obstetrics and Gynecology. 86(2), 163-169.

[2]. Acharya, D.R., Bhattarai, R., Van, T.E., and Chapman, G. 2010. Factors associated with teenage pregnancy in South Asia. Health Science Journal, 4, 1-13.

[3]. Chedraui, P., Hidalgo, L., Chavez, M. and Glenda, S.M. 2004. Determinant factors in Ecuador related to pregnancy among adolescents aged 15 or less. Journal of Perinatal Medicine, 32, 337-341.

[4]. Dutta, D.C. 2008. A Text Book of Obstetrics, $6^{\text {th }}$ ed. Chapters: Perinatology and Contraceptoon.

[5]. Eastman, N. and Hellman, L. 1966. William's obstetrics, 13th ed.. New York: Appleton-Crofts.

[6]. Mehra, S., Agrawal, D. 2004. Adolescent health determinants for pregnancy and child health outcomes among the urban poor. Indian Pediatrics, 41, 137-45.

[7]. Rathavuth, H., Ruiz-Beltran, M. 2007. Impact of prenatal care on infant survival in Bangladesh. Matern M Child Health J.11, 199206.

[8]. Save the Children. 2004. State of the World's Mothers. Children Having Children. Westport, CT, USA. 
[9]. Stone, N., Ingham, R.and Simkhada, P. 2003. Knowledge of sexual health issues among unmarried young people in Nepal. AsiaPacific Population Journal, 18, 33-54.

[10]. Viegas, O.A., Wiknsosastro, G., Sahagun, G.H., Chaturachinda, K. and Ratnam, S.S. 1992. Safe childbirth needs more than medical services. World Health Forum, 1913, 59-65.

[11]. World Health Organization. 2005. Facts and figures from the World Health Report, Geneva.

[12]. WHO, UNICEF. 2001. Antenatal care in developing countries. Promise, achievements and missed opportunities. An analysis of trends, levels and differentials 1990-2001.

[13]. WHO, UNICEF, UNFPA.2015. World Bank and the United Nations Population Division. Trends in Maternal Mortality: 1990 to 2015. 